\title{
Border Crossings and Intra-National Trespasses: East German Bodies in Sasha Waltz's and Jo Fabian's Choreographies
}

\author{
Jens Richard Giersdorf
}

On November 10, 1989, when we walked toward the Wall dividing East and West Berlin, we already knew how to walk for a cause, how to walk for change, after months of participating in demonstrations throughout Leipzig and other East German cities. This walking was never a stroll, nor was it Benjamin's flaneuring. ${ }^{1}$ It was also not a resolute hike toward a clearly demarcated goal. Rather the power of the walk was obtained through the impact on the space in which it occurred. This walk was a forceful attempt to gain new space. We did not know if the border guards would put a stop to our walk once we arrived at the checkpoint. ${ }^{2}$ This uncertainty about the outcome made us all hyper-aware of our spatial choices as well as the choreography of our body postures while walking toward the Wall. This awareness differed from our daily consciousness of surveillance by the East German Intelligence Service. ${ }^{3}$ Still, the choreographic tactics that we learned as a result of the experienced surveillance informed our movements.

Jens Richard Giersdorf is a Lecturer A in Dance Studies at the University of Surrey, Guildford. He has published on theatre, dance, and social movement in TheatreForum, Communications, Theater, and Tanz Aktuell.

I would like to thank Susan L. Foster, Yutian Wong, Rebecca Rugg, Jennifer Doyle, Maura Keefe, David Román, and Ned Gusick for their readings of this work. I also thank all participants of the international working group on Choreography and Corporeality at the 2002 International Federation for Theatre Research conference in Amsterdam for providing me with their specific national views on my writing.

${ }^{1}$ Walter Benjamin, Das Passagenwerk (Frankfurt am Main: Suhrkamp Verlag, 1982). Benjamin's employment of "Flanieren" refers also to the German use of the word that connotes more than a simple strolling. It also encompasses a walking along some scenic path, in a park, or along window displays. The action is as much about enjoying the surrounding as being seen while doing so.

${ }^{2}$ Armed border patrols guarded those checkpoints along the border between West and East Berlin. After the building of the Wall, the East German government established those checkpoints to allow West Berlin citizens to come to the East. However, the reverse movement of East Berliners toward the West was highly restricted and mostly took place at Bahnhof Friedrichstrasse.

${ }^{3}$ This awareness of one's own corporeal identity was captured by one of the most famous writers in the GDR, Christa Wolf, in her novel Was bleibt. Christa Wolf, What Remains \& Other Stories, tran. Heike Schwarzbauer, Rick Takvorian (Chicago: University of Chicago Press, 1993). Was bleibt was written in the summer of 1979 and reworked in November 1989, the month of the fall of the Berlin Wall. The text describes a day in the life of the author. It elaborates the results of Christa Wolf's observation by the state's Intelligence Service (Staatssicherheit, Stasi) in a period of intense intimidation of intellectuals, and in particular, artists. The book records her increasing awareness of her own body, her movements, 
An elderly woman passed me. She seemed determined to make it to the other side. She probably remembered her childhood when she had been able to visit her relatives who lived there, before it became "the other side." The woman's long striking steps belied her age. She knew that she had to make it across that border, or she might never have the chance again. A short man next to me seemed hesitant in his approach and lowered his gaze when I looked at him. His leather jacket and polyester bag made his association with the Intelligence Service most likely. Why was he going? Wasn't he supposed to prevent the very movement in which he participated? Had he been sent to report on the citizens' movement toward the border?

We looked at each other and realized the collective power created through our walking. Yet, we also sensed the individual choreographic choices in that pattern. This walk did not expand our movement vocabulary; rather it made us experience the familiar movement anew. As we moved up to the checkpoint, fear made us begin almost to march. We attempted to conquer rising emotional responses to the unknown situation with more confident body language. We took more ground with our steps and lifted our knees higher. We put more weight on our feet as they hit the ground, and we rolled them with more pressure over the pavement. As we arrived at the line in front of the checkpoint, we straightened our backs, held our heads up slightly higher. Thus, when the gaze of the border guard who checked our documents hit us, we appeared confident and in control of the situation.

Gradually walking onto the bridge after he gave us the necessary stamps in our papers, we felt swept away by the movement around us. ${ }^{5}$ Yet, slowed down by the masses in front, no one was able to rush to the other side of the bridge that connected us with the Western part of Berlin. Deliberately putting one foot in front of the other, I walked in astonishment over that bridge. The actual crossing was unbelievableoutside of the realm of any imagined possibility. I started to see myself as though from an outside perspective. How did my body look in this space and moment, which later became the focus of worldwide news, the subject of movies and books? I saw myself looking at people and at the machinery that protected the border. I felt the slight push from the bodies behind me, the tension of my neighbors, and the pull of anticipation of the bodies in front of me. I watched myself consciously incorporating my observations of my body's movement and the movement of the surrounding walkers

her fear, and her psychic insecurity due to an obvious surveillance by the Staatssicherheit. By writing about the observation and her reaction to it, Wolf attempted to realize the changes of her own body and movement. The obvious and constant observation resulted in an increased self-observation. Every move and each body posture could reveal something to the observer. The smallest detail became important. The only comparison I could give for a reader to understand the observation's influence on the body would be the effects of an illness. There is always the possibility to get sick. Everyone knows that. The appearance of pain results already in a different awareness of one's own body. This awareness changes dramatically after someone is diagnosed with an illness. From this time on, the whole body, each movement, body posture, and even the way someone is motionless is constructed around the illness.

${ }^{4}$ This unofficial uniform consisting of leather jacket and polyester bag became a signifier for members of the Stasi. Thus, East German citizens were often able to spot the undercover agents and observers. Of course, there is the likelihood that the Intelligence Service wanted us to see some of their agents to create a panoptical situation in a Foucaultian sense.

${ }^{5}$ The bridge is Oberbaumbrücke, which served during this day as one of the first hastily opened makeshift checkpoints. 
into my own. This awareness of my corporeal senses even as I visualized myself among the other walking bodies created my sense of spatial and historical significance. As I later learned, I shared that comprehension with many of my fellow walkers. The conscious reflection on the double perspective of that walk on the bridge- the outside view of the body and the sensations inside the body-created the historical moment.

This re-creation of the choreography of a pedestrian movement provides a social, political, and methodological context for this essay in which I relate two dance productions to the aforementioned social movement. Both choreographies take stances on the political situation in East Germany during and after the opening of the Berlin Wall in 1989, though one is by a West German and another by an East German choreographer. Our walk across the boarder ultimately informed these dance productions, both thematically and choreographically. Examining the dialectic relationship between bodies' conscious movements during a historical walk across the border on the one hand and diverse contemporary choreographies as interrogations of such movements on the other exposes shared choreographic and social mechanisms. In other words, an interrogation of the interdependence of the artistic exploration and its seemingly vanished cultural and corporeal referent enables a theorization of bodies and their embodiment of a society's past, present, and even future structures. This approach is inspired by the thinking of Mark Franko, who argues in his article "Mimique," ${ }^{\prime \prime}$ for a related rethinking of performance, and in specific, dance, through the terms "presence" and "disappearance." Franko works against the common notion of dance's ephemerality that has glorified but also trivialized and marginalized dance and consequently the body. The widely used phrase, "the disappearing body," ceaselessly casts bodies as only temporarily appearing in space and time, and therefore as reducible to an essence, which belongs to its own system outside of all cultural systems. This approach to bodies and performance removes the performing subject (and here again especially the dancing subject) from cultural and political issues.

Questioning this notion, Franko repositions corporeality back into culture by investing movement and performance with a capacity to perform over again. The movement and performance would be able to produce not only the past and a present, but also a future. Therefore not only does the sociocultural system produce certain bodies and movements, but also bodies and embodiment themselves produce far more than just memory. Based on this understanding, bodies have to be analyzed as cultural constructs but also culture as created through embodiment. ${ }^{7}$ It is with this notion of corporeal agency, by acknowledging bodies' capacity to create social systems, that I want to look at corporeal practices that are both theatrically staged dances and pedestrian movements.

\footnotetext{
${ }^{6}$ Mark Franko, "Mimique," in Bodies of the Text, ed. Ellen W. Goellner and Jacqueline Shea Murphy (New Brunswick: Rutgers University Press, 1995), 205-16.

${ }^{7}$ Susan Leigh Foster, "Dancing Culture," American Ethnologist 19.2 (1992): 362-66. This book review is one of Foster's earlier demands for a recreation of embodiment in writing as the only way to theorize the double relationship between society and the body. I situate my writing and theorizing inside this subsequently established tradition of dance scholarship.
} 
My initial description of such a pedestrian movement sets up the subsequent binary between a West German and an East German choreographers' staging of East German identity. By literally moving across the border (a discursive as well as a literal one) the walk bridged two distinct national identities, which informed the choreographers' view on East German corporealities and movements. ${ }^{8}$ Even though choreographers Sasha Waltz and Jo Fabian both depict East German identity around the reunification and the fall of the Wall, their distinct approaches and trainings produce dramatically different choreographies. Yet, this is not meant to ground my analysis of the two choreographers' work primarily in their origin on either side of the Berlin Wall. Rather, the critique of their disparate views on the East German socio-political system utilizes an analysis of their dances and choreographic processes. Often discourses on societies' structures refer to bodies as symptomatic corporeal sites. Only recently have scholars and choreographers located bodies and their movements at the center of their explorations as creators of social systems. ${ }^{9}$ Readings of corporealities and choreographies on and off stage are among the techniques that return agency to bodies as the main protagonists of historical movements. ${ }^{10}$

And it is precisely the differing location of agency in their choreography that becomes most essential for a comparison of Waltz's and Fabian's productions, particularly in relation to the historical walk across the Berlin border. This walk amalgamated the double perspective of an internalized awareness of a social referentiality of movements with the outer experience of that movement's historical significance. Michel de Certeau's brilliant analysis of walking through Manhattan provides the ground for charging the walk across the bridge with such potentials. ${ }^{11}$ By defining "walking as a space of enunciation" he affirms that walking creates more than just a one-dimensional choreographic pattern in a geographical or architectural structure. ${ }^{12}$ For de Certeau, walking contracts, extends, inverts, and invents space by appropriating

\footnotetext{
${ }^{8}$ In the walk East German citizens cross the bridge between those two separated German countries from the East to the West. This movement reversed a movement that West German citizens were always able to perform. My view on the walk across the border and the two dance productions is informed by this unexpected reversal as well as my former East German citizenship.

${ }^{9}$ Dance scholars theorize a variety of bodies. Very often, we are confronted with scholarship that applies the term "body" in an abstract or metaphorical way. There is nothing wrong with these employments of the term "body." However, we can clarify the various levels of abstraction. What is the relationship between bodies as flesh and the metaphorical use of the term "body"? In her essay "Bodies-Cities," Elizabeth Grosz describes how society culturally influences the body's potentials through disciplining, regulating, administrating, and training. Grosz goes on to state that individual bodies interconnect with other bodies and objects. Considering this definition we could endeavor to interrogate the connection of the body to its abstractions, within ideological, cultural, religious, or technological re-configurations. Elisabeth Grosz, "Bodies-Cities," in Sexuality and Space: Princeton Papers on Architecture, ed. Beatriz Colomina (Princeton: Princeton Architectural Press, 1992), 241-54.

${ }^{10} \mathrm{I}$ work in a tradition of dance scholarship with this notion of corporeal agency. Authors such as Susan L. Foster, Susan Manning, Mark Franko, Marta Savigliano, Randy Martin, Janet AdsheadLansdale, Ramsey Burt, and Lena Hammergreen not only created the new focus of dance studies, they also enabled dance studies to interact and enrich other disciplines. See their work for an impressive variety as well as level of research in dance studies.

${ }^{11}$ Michel de Certeau, The Practice of Everyday Life, tran. Steven Rendall (Berkeley: University of California Press, 1988), 91-110.

12 Ibid., 98.
} 
and embodying the space through which it moves. Walking also creates relationships with other geographical, social, and discursive spaces by connecting them and by erasing the distances between them. Yet most importantly, walking always moves with an entire "tree of gestures" through space, thus multiplying meaning. ${ }^{13}$ Walking produces a relationship with the authorial space but also recalls memory and with it the influences that structured the space and the walk.

Even though de Certeau is mostly interested in pedestrian enunciations that resist disciplinary structures, he still positions them inside an administrative, ideological, and panoptical space without the power to overthrow these disciplinary structures. ${ }^{14}$ In addition he requires an elevated and voyeuristic position to enable the readings of a walk's inherent meaning and agency. For de Certeau the people walking through space are not capable of grasping their complex corporeal practice, let alone employing this understanding to dramatically change the structures in which they move. ${ }^{15}$ Yet, as the walk across the bridge demonstrates, the position of the elevated observer and the involved practitioner can be integrated, and in turn this could lead to a complete transformation of the space in which the walking occurs. Jo Fabian understands that integrative double perspective not only as necessary for the creation of a new social order but also as clearly assigning agency to the body. He is able to communicate his comprehension to the audience by translating it into a compelling choreography that explores in multidimensional tableaus how citizens adjusted their moving bodies to the collapse and subsequent re-creation of societal structures. Sasha Waltz, however, does not explore the connection between movements and their social referent and the role that bodies play in the creation of social systems. Yet owing to her spectacular movement vocabulary and visually striking arrangements, Waltz currently inhabits the place of Germany's most sought-after theatrical export. Her popularity and invitations to perform abroad have even exceeded Pina Bausch's world-famous Wuppertaler Tanztheater. Waltz has two companies that perform her work abroad, and additionally, she shows her choreographies at the famous Schaubühne in Berlin, which she co-manages. ${ }^{16}$

At the beginning of her career, Sasha Waltz studied dance in Karlsruhe with Waltraud Kornhaas, a pupil of Mary Wigman. ${ }^{17}$ Wigman's legacy of a non-narrative

${ }^{13}$ Ibid., 102.

${ }^{14}$ Ibid., 96.

${ }^{15}$ Ibid., 92-93.

${ }^{16}$ Her more recent pieces Körper (Bodies) and $S$ have been playing to sold-out houses since they premiered at the Schaubühne. The choreographer became the darling of glossy magazines such as the German editions of Elle, Vogue, and Cosmopolitan. As reported, the influential weekly German news magazine Spiegel even depicted Waltz as one of tomorrow's most powerful Germans. Michaela Schlagenwerth, "Jedes Mal ein Schritt über die Grenze," Berliner Zeitung, 9/10 June 2001, 5.

${ }^{17}$ Wigman, who was one of the most influential creators of German modern dance (Ausdruckstanz) between the two world wars, situated her work at the intersection of early feminism and nationalism. Her choreographies reacted against the narrative form and the position of women in story ballets. Wigman emphasized movement interrogation and blurred gender connotations through her use of costume and mask. Her dances transcended the individual dancer into an abstract structure. Often, her choreographies revolved around the relationship of a leader and a group, where she expressed an elitist view regarding the position of the leader through dance. Even though Wigman employed 
approach to choreography, her abstraction of individuality, and her preference of a set performed final piece remains influential for Waltz's choreographic style. Following her studies with Kornhaas, Waltz attended the School of New Dance Development in Amsterdam. The school has an international reputation for its focus on contact improvisation. ${ }^{18}$ The technique of contact improvisation has had a big influence on Waltz's creative process by serving as a major tool for the re-evaluation of movement vocabulary both for her dancers and her choreographies. Yet, guided by her earlier Wigman-influenced training and its orientation on established stage choreography, Waltz's dancers rarely improvise on stage. Rather, much of Waltz's movement vocabulary material builds on contact's negotiation of weight and encounter as a choreographic component. Three years after her study in Amsterdam, Waltz exposed herself to yet another approach to dance that relied on collaboration with other arts, such as the fine arts and contemporary music, during a stay in New York City.

Returning to Germany, she founded Sasha Waltz \& Guests in $1993 .{ }^{19}$ Waltz's first piece with this new company Twenty to Eight, the initial part of her Travelogue trilogy, earned her the prize for choreography at the International Choreographers Competition in Groningen. In 1996, Waltz opened the Sophiensäle, a performance place in East Berlin with her original choreography Allee der Kosmonauten, the piece that established Waltz's current fame and which is still toured extensively by one of her companies. In 1997 Allee der Kosmonauten was invited to participate at the annual German theatre festival Theatertreffen in Berlin. During the following year, Waltz adapted Allee der Kosmonauten into a film in collaboration with the two government-sponsored TV stations. The original choreography on which the film was based won the prestigious Adolf Grimme Award for Outstanding Individual Achievement for writing, directing, and producing in 2000.

improvisation as a working tool, she repeatedly spoke out against improvisation as a stage form. For a groundbreaking study of Mary Wigman's multifaceted career, see Susan A. Manning, Ecstasy and the Demon: Feminism and Nationalism in the Dances of Mary Wigman (Berkeley: University of California Press, 1993).

${ }^{18}$ Contact improvisation, a movement practice developed collectively in the United States in the 1970s, is a social and artistic movement in which two or more dancers negotiate weight and space based on democratic values. Even though contact improvisation offers principles for a way to move, it does not provide a set vocabulary. Contact dancers are encouraged to pay close attention to their bodies, which are approached and employed as intelligent systems. The parameters of the choreographic choices vary depending on the school and training of the participants. Cynthia Novack provided the first survey of contact improvisation as both an artistic and social movement. Cynthia J. Novack, Sharing the Dance: Contact Improvisation and American Culture (Madison: University of Wisconsin Press, 1990). The School of New Dance Development in Amsterdam is strongly influenced by a North American based approach toward contact improvisation, which only recently came under critique as a nearly exclusively white, often middle class dance form, which does not always recognize its place in a complex dance genealogy, by emphasizing its pioneering inventiveness and break with any preceding tradition. For the most recent and comprehensive analysis of contact's and other forms of improvisation's employment of Afro-Caribbean and Asian choreographic principles, see Susan L. Foster, Dances That Describe Themselves: The Improvised Choreography of Richard Bull (Middletown: Wesleyan University Press, 2002). Building on research of dance scholars who interrogate the influence of non-white dance forms on modern dance as well as scholarship on Jazz and improvisation in music, Foster establishes a genealogy that questions the established narrative of the self-generating origin of contact and improvisation in North America in the 1970s.

${ }^{19}$ She founded the company in collaboration with Jochen Sandig. 
Allee der Kosmonauten translates as Avenue of the Cosmonauts, which is one of the major boulevards leading through a suburb of East Berlin that consists solely of large and identical apartment blocks. The East German government built these suburbs to provide affordable housing for its citizens in an expeditious manner. Often, the development of an infrastructure could not keep up with the rapid construction of these houses. As a result, these suburbs became an icon for anonymous living in the East bloc for many Westerners. While North American living spaces on the outskirts of cities are largely middle-class and upper-middle class privately owned homes that have been constructed to shield their owners from the rigors of city living, the apartments in the East German suburbs are mostly rented by their inhabitants and do not fulfill the dream of property ownership as is often the case with North American suburbs. After the reunification, middle class citizens left the East German suburbs either to live in the center of the cities or to move even further outside the city, to their own houses. As a result of that migration, only working-class families remained in the government housing. These families were hit hardest with unemployment due to the dismantling of East German industries after the reunification. Often, an entire family became unemployed and even the younger family members who still went to school had no chance to receive a job-oriented education. In their desperation and in search for a meaning for their situation, these disillusioned young men and women sometimes turned toward right-wing, racist, and neo-Nazi organizations. All these developments furthered the reputation of East German suburbs as an undesirable area overrun by lower-class citizens who engage in violent, meaningless behavior.

For the creation of Allee der Kosmonauten, Waltz went to the government housing projects in East Berlin and interviewed citizens of the former German Democratic Republic (GDR, East Germany). She crossed the former border from the West to the East after the Wall came down to investigate East Germans' lives in the newly unified Germany. As Waltz repeatedly reports, she went to the East Berlin projects and simply knocked on doors. ${ }^{20}$ Raised in West Germany, she wanted to explore a life that she knew nothing about. As Waltz recounts, the people in the projects were at first reluctant to open their doors and lives to her. ${ }^{21}$ Waltz seems to be surprised about that reluctance, despite the fact that in 1996, while Waltz was creating her piece, German media reported daily about new revelations about the depth of reach of the Stasi, the East German's Intelligence Service. The majority of these reports depicted the former socialist citizens as cooperative or at least as affirmative onlookers. East Germans' paranoia and mistrust toward West Germans were furthered by these reports. With an awareness of East German history, how was Waltz able to think that she, a stranger, could just knock on East German doors and be let in? Not only did the former East German citizens learn over forty years to be careful with strangers as they might be

\footnotetext{
20 "'I started by simply ringing doorbells,' recalls Sasha Waltz. The search for a new ideal led her into a world she never knew: life in a former East Berlin quarter in a street called 'Allee der Kosmonauten,' where apartments all had the same layout. Despite different furnishings, the focal point of each apartment was always the sofa, which stood in exactly the same part of the living room." Press Release, Advertisement. Newsrelease The Barclay \& Cheng Hall, 3 January 2001.

21 "The strangers who answered were at first reluctant to talk to me, but soon the ice was broken, and once we established a trust, they began to tell me stories of their lives." Ibid.
} 
involved with the Stasi, they also might not have wanted to open up to a West German, because of a legitimate fear of uninformed and generalizing judgment by one of their Western co-citizens. As Waltz's piece shows, they might not have been too far off in their fear. What promises, through its title, to be the depiction of a very specific social situation turns out to be a universalized interrogation into inner-family constellations that do not leave the realm of established stereotypes.

Waltz's methodology for the creation of her piece recalls highly critiqued procedures of early anthropological studies that did not problematize the power structure created by the observer, on one side, and the observed or native informant, on the other. This model of anthropological studies has been shown to be complicit in the West's creation of an oppressed and exoticized Other by scholars such as Edward W. Said and Gayatri Chakravorty Spivak. ${ }^{22}$ Unaware of her impact on the referent of her piece as well as the limitations of her point of view, Waltz states the following: "For me the most important thing about the work was to paint a transparent view of the communal life of a family, without judging, sympathetic and ironic, loving and cruel." 23 With this declaration Waltz displays that she grasps neither the influence of her own subjectivity that informed the choreography of the piece nor its inherent power.

Her non-reflective position regarding societal power structures also informs her choreographic and dramaturgical choices, which are established with Allee der Kosmonauten's earlier scenes. A man on a sofa appears reduced to a torso that bumps and rolls around a piece of furniture. Gradually, the rest of the body becomes involved with this acrobatic exercise. As a result, various body parts begin to manipulate one another like props, with no hierarchy provided between the body parts and the sofa. Through movement quality and emphasis, the sofa becomes an equal player in the interaction between body and furniture; the sofa bounces the man back, the same way that his own hand is pulling him up and pushing his torso from side to side. Waltz immediately presents a spectacularized version of daily gestures-in this case the sitting and lying on a sofa. The appeal of her choreography derives from an overdrawing of those gestures and the surrealistic managing of props. Yet, it also equalizes bodies and props and as a result objectifies bodies (Fig. 1).

Waltz often starts with such random collisions of a human body and a prop and then explores all possibilities catalyzed by the initial encounter. Even though she also turns to the more private issues of relations between men and women without

\footnotetext{
${ }^{22}$ Gayatri Chakravorty Spivak, Can the Subaltern Speak, in Negotiating Performance: Gender, Sexuality, $\mathcal{E}$ Theatricality in Latin/o America, ed. Diana Taylor and Juan Villegas (Durham: Duke University Press, 1994), 66-111. Edward W. Said, Orientalism (New York: Pantheon Books, 1978). There is of course a difference between the racially marked Other and the Other that is marked by political systems, nationhood, and class. However, not only does dance studies as a fairly new discipline has to employ appropriate methodologies and tools from other disciplines, it is also necessary to theorize the visually and nationally undifferentiated Other, such as the citizens of many Eastern European countries. This analysis would have to focus on the interdependence of class, nationality, and culture in relation to already established notions of a racially marked Other, because the already existing predominantly North American discourse on race rarely encompasses the racial differences inside Europe, which are often related to class and nationhood.
}

${ }^{23}$ Newusrelease The Barclay \& Cheng Hall, 3. 




Figure 1. Bodies as props. Sasha Waltz \& Guests' Allee der Kosmonauten. Photo: Thomas Aurin.

ignoring established sociological dimension of these gender relations, Waltz seems more interested in the spatial and physical constellations that occur when various people inhabit confined rooms. She explores places as well as the way bodies inhabit them. She might begin her investigation with an observation of how one positions a hand while opening a door, or the angle at which someone holds a knee in order to take a step on a stair. Occasionally, an absentminded and vigorous petting of a cheek intensifies into hitting; an unexpected turn of one body toward another makes the second body shrink back and results in an elaborate choreography of swings and vacillations. Or, in the instance of the beginning of Allee der Kosmonauten, she looks at all possible - or even impossible — ways a body inhabits a sofa or a sofa engulfs a body. These variations extend spatially and take over progressively more body parts. Through this type of abstraction, the movements move further and further away from their original circumstances, and with it, from the social situation that caused them.

These choreographic principles are at the core of Allee der Kosmonauten, which Waltz describes as belonging to her less abstract period. ${ }^{24}$ Some of the dancers are easily recognized as characters given their attire and their relationship to one another. An old-fashioned man and a woman clad in a housedress seem to be the father and the mother of a family. A girl and a boy are dressed in children's clothes, and their movement quality can be read as more childlike than the other characters. An

\footnotetext{
${ }^{24}$ In an interview with the Berliner Zeitung, Waltz explained her current return to more abstracted dance pieces. She expressed that she arrived with her more narrative work at a dead end and subsequently rediscovered the more fragmented and abstracted approach of her earlier work such as Twenty to eight. Schlagenwerth, "Jedes Mal ein Schritt."
} 
additional couple in tacky adolescent clothing could be another son with his girlfriend. ${ }^{25}$ Yet, these probable relationships are challenged by scenes where apparent siblings play out sexual interactions. Of course, Waltz might be indicating an incestuous situation, as these moments often become violent in her choreography. During these eruptions of violence, the majority of the audience, initially amused and entertained by the actions on stage, turns quiet and slides uncomfortably in their seats. ${ }^{26}$ Yet, soon they are preoccupied again by the next athletic movement sequence (Fig 2).

Such an acrobatic encounter occurs halfway into Allee der Kosmonauten when all characters except for the father, who accompanies them with his accordion, join into a dance. The older son initiated this abstract dance by slowly turning while holding a board on his shoulder. In order to avoid getting hit by the board, the other son, daughter, and girlfriend, who had positioned themselves earlier next to the older son, have to bend forward or backward, depending on the direction of the board's rotation. Gradually, this movement gains momentum, travels to the lower parts of their bodies, extends spatially, and even takes over the mother at the other side of the stage. The



Figure 2. Collision of bodies. Sasha Waltz \& Guests' Allee der Kosmonauten. Photo: Matthias Zölle.

\footnotetext{
${ }^{25}$ Waltz describes them as three generations. Program for Allee der Kosmonauten at the Sophiensäle, Berlin, 09.26.1996-10.20.1996.

${ }^{26}$ I experienced two very different audiences while watching Waltz's choreography. The first audience consisted of mostly hip East and West Berliners for the premier-run of the piece at the Sophiensäle in 1996. The second was a much older and more conservative audience attending the performance at Irvine's (CA) The Barclay Theater in 2001. The audience observing Allee der Kosmonauten rarely reacted as a homogeneous group to the shown choreography. Yet, I observed shared moments of enjoyment and discomfort during both performances.
} 
initial ducking movement transforms progressively into rotations and turns of the dancers, who aligned themselves into a formation. Finally, walking stiffly on their heels, the dancers perform sudden swirls and turns as if participating in some folk or social dance. Yet, they swing their arms independently from the rest of the body, thus making their arms seem as only being attached to the body without any capacity to initiate movement. This sequence is the only part of Allee der Kosmonauten where the dancers move in an obviously choreographed dance formation across the floor. However, they challenge the employment of more traditional dance movements with their exaggerated execution, the swinging of the apparently uninvolved arms, and the awkward walking on heels. The movement quality and the contradictory control of torsos and limbs invite a comparison with marionettes, which do not control their own movement.

This sequence encapsulates how Waltz choreographs agency outside the dancers' bodies. Waltz's employment and location of movement vocabulary emphasize the bodies' complete absorption into a highly acrobatic situation without illuminating the social reasons for these situations, and without situating the initiation of movement from the bodies themselves. Whereas the walkers who crossed the border in Berlin were consciously reflecting on their movement vocabulary, spatiality, and choreographic choices to include their observation into the choreography of the walk, Waltz's dancers are moved by an unidentified external force. The exclusive focus on movement variations without exploration of cause, motivation, or solution provides an entertaining affirmation of the present moment, but it does so by sacrificing past embodiments and bodies' capacity to choreograph the future.

The final scene of Allee der Kosmonauten affirms this analysis. The dancers unite again for the end of the production, where they fight viciously with each other around the sofa that is now surrounded by relatively few props. The fight is continually interrupted as the music abruptly stops and the family members fall into a sudden sleep. After a number of repetitions of this externally initiated action-sleep sequence, the characters unanimously freeze several times amidst their current activity. These unexpected moments of stillness do not provide a calming atmosphere on the stage; rather, their bodies appear to surrender to exhaustion. More importantly, the tableaus depict the bodies in mid-fight or engaged in a situation that depicts boredom and unhappiness. Finally, a blackout ends the piece during one of these tableaus.

Over the course of the evening, Waltz stages the passions, the joyless existence, the brutality, and the boredom of a family unit. All of the dancers move in high frequency, like comic figures. They fold their entire bodies up only to open themselves up again in a gymnastic fashion. They suddenly fall into a motionless sleep that seems to provide them with the power to burst into yet another fight. As in a cartoon, the dancers' action and mishandling of each other's bodies never leave any lasting impact. With a change of music or an interruption by other characters, the dancers' focus shifts from their current activity, and with seemingly perpetual power, they turn their full attention and physical stamina toward their next action. As a result, Waltz's movement interrogations don't lead to any solutions or even a creation of an opportunity that would empower the involved bodies. Waltz deprives the dancers' bodies of their expressive intelligence by restricting their actions to reactions to collisions and chance 
encounters without much resistance or antithetical responses; there is never an opportunity that would authorize the dancing bodies to initiate change.

She also constructs the audience members as passive consumers of a spectacle. By terminating the piece with a blackout on one of the arranged tableaus, Waltz suggests a continuation of this choreographic interrogation of a dysfunctional family. As a result, the family interactions stand as a metonym for a much more eternal narrative that could go on long after the audience's departure from the theatre. Neither the fragmented structure of the piece nor Waltz's choreographic choices require any involvement on the side of the audience. Rather, the spectacularized movement vocabulary and the repeated interruptions of the depicted family life at the end of the production position the audience as astonished observers. Waltz's one-dimensional imagination of East German identity and the resulting physicalization in the dancers' and spectators' bodies does not grasp the conscious choreography that East Germans were capable of creating.

A comparison of Waltz's production to Jo Fabian's choreographic representation of East German identity in his piece Pax Germania further illuminates these deficiencies in her work. Whereas Waltz reduces bodies to responding objects in her display of East German identity, Fabian re-creates the actual transformation process for East German citizens on the bodies of the dancers as well as through the audience members. Trained as an actor in the early eighties, Fabian is a member of the generation that no longer engaged with the socialist system in East Germany. At the end of the seventies and the beginning of the eighties, this new group of artists created a specific form of resistance to that system. Unlike their predecessors, who either supported the socialist regime with a more or less critical distance or openly opposed it, these artists "ignored the GDR inside the borders of the GDR." ${ }^{27}$ The new generation neither identified with the socialist ideal nor joined underground opposition groups. Fabian's contemporaries refused to function in the state-opposition-model. They drew from a lexicon of nonsocialist ways of life in an attempt to create their own reality.

The importance of this artistic subculture derived from its individual breaking with the structures of the socialist system. These artists still used state resources, but only to enable their lifestyle, one that stood in contrast to the socialist ideal. A major component of this lifestyle was the artists' unwillingness to function as a part of the socialist collective. The artists of the 1970s and 1980s developed their art by focusing foremost on individuality. Fabian joined the movement by leaving an established career in state theatre and by working in the margins of government-sponsored theatre from 1984 until 1989. This marginalization enabled him to produce work that departed in style, content, and focus from the official theatrical discourse in East Germany and its dominating traditions of Bertolt Brecht, Socialist Realism, and Heiner Müller's apocalyptic historicism.

For instance, Fabian's utilization of slow motion in many of his early pieces distanced his choreographies from their original source in everyday movement. The audience observing this temporally extended variation of pedestrian movement was

\footnotetext{
27 "Sie 'ignorierten die DDR in den Schranken der DDR'" was phrased by the painter Moritz Götze, who was born in 1963. Paul Kaiser and Claudia Petzold, Boheme und Diktatur in der DDR: Gruppen, Konflikte, Quartiere 1970-1989 (Berlin: Deutsches Historisches Museum, 1997), 68.
} 
forced to re-evaluate their knowledge of it. This re-evaluation removed the dancers' bodies from any immediate reference to the world outside the theatre. A North American audience might be familiar with this employment of slow motion as an aspect of postmodern dancers' investigation of bodies, movement, and social space. ${ }^{28}$ Yet Fabian's use of slow motion was quite distinct in the historical context of the GDR; no other East German choreographer at that time utilized movement as consciously as Fabian to critique predominant socialist theatre practices. In Fabian's work, slowly moving bodies created their own reality inside the socialist system. In conjunction with the individualization, this approach illustrated the disengagement of Fabian and his generation from the East German socialist system. Correspondingly, Fabian destroyed, or at least questioned, the hierarchy of modes of representation in socialist theatre at that time. This theatre was constructed on the principles of Socialist Realism and favored the vocalizing actor's body as the main theatrical tool. This preference had its roots in the distinct construction and function of Socialist Realism.

In her groundbreaking and thorough analysis of the interrelationship of politics and early GDR theatre, Petra Stuber reveals Socialist Realism as everything but a realistic depiction of the world. ${ }^{29}$ On the contrary, through an analysis of theatre history and theatre politics, she defines this kind of realism as an art form that favored an illusionary and ideal depiction of reality. Only through a complex historical redefinition of realism were the communist leaders of the GDR able to employ it as the main tool for the development of an East German national identity. ${ }^{30}$

This re-signification of realism into Socialist Realism was based on the definition of the term by Andrej Zhdanov at the 1st Congress of the Soviet Writers' Union in 1934. His definition demanded the portrayal of a postulated totality of reality and a penetration beneath the surface appearance of reality in order to grasp the underlying laws of historical change. ${ }^{31}$ Such an understanding of art defines concepts and appearances in society as social constructions. Yet, the laws that construct them as well as an underlying essence remain outside of and uninfluenced by these concepts and appearances. To assume that it is possible to work through all the concepts, names, and appearances to advance toward the unaltered essence is an Idealist position. Thus,

\footnotetext{
${ }^{28}$ Sally Banes, Terpsichore in Sneakers: Post-Modern Dance (Middletown: Wesleyan University Press, 1987). See Banes's book as a good overview of the so-called Post-Modern Dance in North America.

${ }^{29}$ Petra Stuber, Spielräume und Grenzen: Studien zum DDR-Theater (Berlin: Ch. Links Verlag, 1998).

${ }^{30}$ The interesting aspect of the socialist employment of realism was its apparent non-congruence with the GDR state ideology, Marxist materialism.

${ }^{31}$ Jeremy Hawthorn, ed., A Glossary of Contemporary Literary Theory (London: Edward Arnold, 1992), 205. Related to this definition is a debate about Expressionism that took place in Das Wort, a journal published by exiled German artists and art historians in Moscow in 1937/38. This debate went way beyond a definition of Expressionism. Rather, the controversy disputed the function of art in the twentieth century and the relationship between artistic expression and societal conditions. Artists such as Klaus Mann and philosophers like Ernst Bloch demanded new contents, forms, and even a redefinition of structure and function of art as a result of the changed reality at that time. In contrast Georg Lukács, Béla Balázs, and Alfred Kurella called for an art residing inside the realms of classical humanism. Lukács even demanded that art represent the essence of reality in a unifying form. He called for a congruence between the representation of reality and reality. Stuber examines Lukács's definition of art as influenced by Hegel's and Aqina's philosophy in which the essence of reality hides behind its appearance, but where it is nevertheless possible to reveal the essence behind the appearances or concepts. In Lukács's understanding, realism should have exposed the essence of a society as completely as possible. Stuber, Spielräume und Grenzen, 71-75.
} 
the Realists were actually Idealists, and subsequently Socialist Realism was an Idealist art form. ${ }^{32}$ And because the reality of Realism depends on the definition of such reality, GDR officials were able to constantly re-define Socialist Realism to match it to their ideological needs. ${ }^{33}$ In this quest, text-based art forms were favored by the East German government because they depicted socialist reality as well as the laws that created this reality as seemingly unambiguous. Thus, second only to literature, the vocalizing actor became the main artistic tool of Socialist Realism. Enmeshed in complex collective circumstances, actors illuminated the historic significance of their current social and political situation for the development of socialist reality.

This is where Fabian refused to collaborate with socialist theatre conventions. By nearly eliminating speech or disconnecting it from the actors' and dancers' bodies, Fabian withdrew from compliance with this demanding socialist theatrical tradition. He shared this resistance to narrative with other East German directors, actors, choreographers, and dancers, who worked outside or at the margins of state- and citysponsored theatres. This new brand of East German theatre no longer attempted to reveal the driving forces underneath an ostensibly objective reality. Instead, this theatre concurrently emphasized its autonomy and attempted to break down the division between theatre and reality. The new generation of artists achieved this goal by emancipating theatre from text as well as liberating theatre from its function as a political and moral institution. Consequently, the new theatre initially received a strong and negative reaction from the government. But growing attention from East German audiences and theatre experts enabled its survival and even occasional endorsement by the state officials.

Even though his interests were shared by other East German directors, Fabian found his unique voice and style by focusing on the body and movement in his dance theatre pieces. $^{34}$ Tableau-like pictures, perpetual repetitions, slowed-down movements, and various kinds of projections lead to a labeling and even dismissal of Fabian as the "East German Robert Wilson" by West German critics, after the fall of the Berlin Wall in 1989. However, they hastily turned around to declare him the rising star of the offtheatre scene after his invitation to the 1994 Theatertreffen. Fabian's work was the only off-theatre production invited to this important German theatre festival in 1994. Thus, Fabian is unique in that he, unlike other choreographers, was able to move his work from the periphery of state-sponsored East German theatre to the more visible Berlin off-scene after the reunification. In 1999, significant theatres in Germany jointly awarded him the prestigious German Producers' Prize for Choreography. Currently, Fabian receives funding from the Berlin senate and continues to produce controversial new work in collaboration with major off-theatres in Berlin and other cities in Germany.

\footnotetext{
${ }^{32}$ Realists, such as Thomas Aqina stated that the thing behind the name really exists and that it is possible to understand the essence of all things through their names. As a result, Aqina's school of thought defined the names as real. Thus they were named the Realists. Contrary to that, the Nominalists, among them Ockham, understood that the terms and the essence were only names (nomina).

${ }^{33}$ Petra Stuber. E-mail to the author, 4 December 2000.

${ }^{34}$ For a discussion of Fabian's work at three distinct stages of his career and an abridged and earlier version of the analysis of Pax Germania, see Jens Richard Giersdorf, "The Dance Theatre of Jo Fabian: Blown Away, Pax Germania, and Prometheus," Theatre Forum 15 (1999): 90-96.
} 
Throughout his work, Fabian stages bodies to elucidate their intentional construction as both objects and agents in history. ${ }^{35}$ Fabian's view of the body as the main protagonist of historical movement returns agency to the body and creates space for resistance. Thus, not only does his dance theatre explore how a citizen's body is surveilled and enforced into norms of movement and behavior by a government, but Fabian also elaborates the body that performs resistance to those norms. His 1997 production, Pax Germania, added another element to this exploration by placing itself in reference to a concrete political situation. Fabian interrogates how the transformation from the socialist Germany to the united capitalist Germany was induced by the construction and friction of collective and individual identities. Fabian's piece symbolizes the history of the 40 years of the German Democratic Republic, the fall of the Wall, and the time since the reunification on October 3, 1990.

In the opening of Pax Germania an actor walks confidently, but very slowly, onto the stage, shouldering a red flag on a long pole. His body's movement disguises the fact that he carries the heavy device. After he finds his place at the back of the stage facing out toward the audience, he adjusts himself and the flag, which slowly ripples in an artificial wind. Seven actors follow him reluctantly, one by one. They slowly stroll to the back of the stage until they align themselves next to the flag carrier (see Fig. 3). Arranged differently from each other, all of their postures appear casual and seem to indicate an unwillingness to perform. Eventually, a head's tilt, a gaze, or a twitch develops into an action. Without departing from the almost procrastinating pace of the

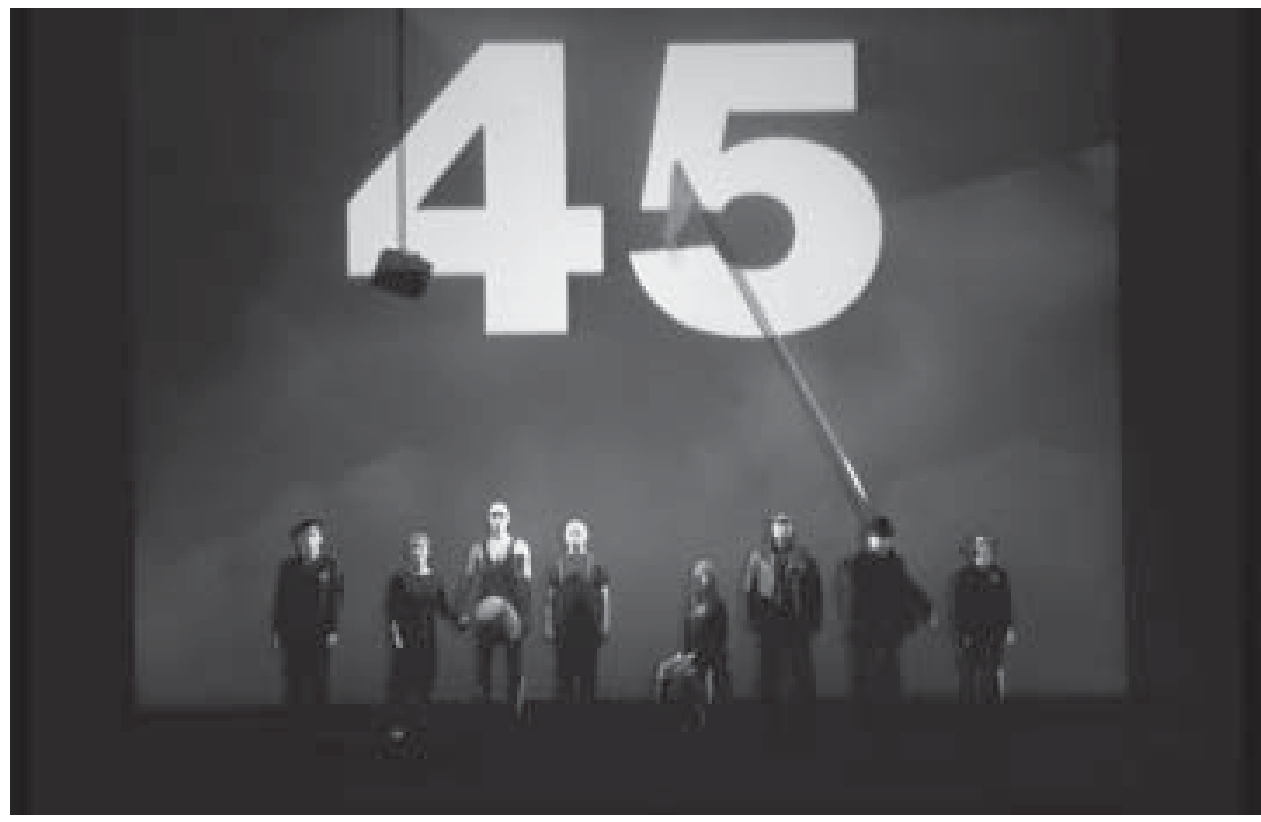

Figure 3. Forty minutes of repetition in a line at the back of the stage. Jo Fabian's Pax Germania. Photo: Andreas Stirl.

${ }^{35}$ In 2000, three years after Pax Germania, Fabian returns with his piece Steinberg-Born To Be Wild to a choreographic interrogation of the post-reunification process and its implications for the citizens of the unified Germany. 
piece, a dancer is slapped and tries to return the aggressive gesture, but he is too short to reach the offender's head. The short dancer's attire-trousers pulled up too high with suspenders, red socks and industrial shoes, and a buttoned down short-sleeved shirt-communicates nerdiness. The offender carries a drum on his waist, but he never plays on it. He only raises the drumsticks high above his head with stretched-out arms and bangs the sticks against each other as if setting the rhythm for the piece. One woman wears a skirt suit reminiscent of the East German party's official dress code. A red carnation, the symbol celebrating the working class struggle, is pinned to her lapel. Constantly smiling as if in embarrassment, she attempts to make contact with the flag carrier. Repeatedly, in an awkward and uncertain motion, this woman puts her head on his upper arm. Another woman sucks desperately on a cigarette and coughs out the smoke until her body is thrown into her neighbor's arms by the violent coughs. His attempts to ease her coughing with slaps on her back turns increasingly into a violent beating.

Meanwhile, a clock ticks on a projection behind the actors. The digital display counts down the minutes like a time bomb. Projected onto a screen behind the dancers are images of water rippling down and clouds gliding. Only slight variations of the above movements stretch out over the first forty minutes. Constant repetition of the slap, cough, drumstick-raise, smile, and beating in conjunction with the fact that none of the dancers move out of the line at the back of the stage give the appearance of stagnation and perpetual boredom. The audience counts the minutes and starts to get annoyed. They slide uncomfortably back and forth on their seats, coughing and clearing of throats. Audience members comment loudly on the non-events on stage. More and more spectators leave, bored and angry, slamming doors on their way out. With their casual behavior, the audience starts to participate in the action on stage. ${ }^{36}$

The interplay between the dancers' bodies on stage and the spectators' bodies reenacts forty years of East German corporeal identity. Fabian does not show a onedimensional critique of the state-enforced official corporeal identity on stage. Rather, he displays the results of and the resistance to that state disciplining with the dancers' actions and the audience's reactions. He is able vividly to capture the stagnation of East German life by employing reduced and restrained movements on stage. The dancers barely move and remain restricted to their position at the back of the stage, a brilliant depiction of East German citizens' literal and discursive immobility under the restrictive socialist regime.

Like the marchers across the border, East German citizens were always hyper-aware of their movement due to the constant surveillance by the Stasi. This awareness might have resulted in a more confined movement vocabulary in public, where excessive movements would have attracted the observers' attention. It also accounts for the finely tuned awareness of the inner experience juxtaposed with the outer self-

${ }^{36}$ I saw Pax Germania at the Theater am Halleschen Ufer, which is known for its support of independent dance productions in Berlin. I deliberately unify differing individual spectators into a general audience body in my reading of Fabian's choreography. I am able to do this because Fabian's piece forces the audience into movements and action comparable to the one that moved across the border. In both cases, the growing frustration forced the spectators or citizens into a reaction that changed the space in which it occurred. And this change was only possible because the critical mass participated as a unified movement of individual bodies. 
observation of the sorts that I described in walking across the border between East and West Berlin. Fabian's use of this idea onstage worked symbolically-revealing with seemingly innocent movements the influence of the socialist state power on its citizens' corporeality. The piece also questions the naturalized claim of the state to hold dominating power over its citizens.

Outside the theatre, these kinds of restrictions in East Germany led to movements in the late 1980s that manifested themselves in a mass withdrawal of citizens leaving the country via the increasingly permeable border between Hungary and Austria. Resistors also began organizing their life outside the socialist space and demonstrating throughout the socialist country. East German citizens broke out of the dictated movement pattern and started to express their dissatisfaction through individual spontaneous actions or alternatively organized demonstrations. Similar to such offstage breakouts, the audience, watching Pax Germania, begins its own resistance: the members either leave the general audience body by walking out of the theatre and slamming doors, or they begin to get collectively organized as dissatisfied customers in the artistic market economy. Increasingly, the audience comments on the non-action on stage and even demands a boost of the minimalist activity.

30 minutes, 20, 10, 5-at last the clock displays 00.00 .00 and stops for a few seconds (see Fig. 4). A male voice declares: "The Third of October 1990—What a Day." This was the date of the German reunification. Finally, the clock runs forward. Confused, the actors seem to break out of their routine and interact with one another and even the audience. Still in a line at the back of the stage, a man steps reluctantly forward only to return to the line-up with the other dancers, unsure of his own boldness. Soon

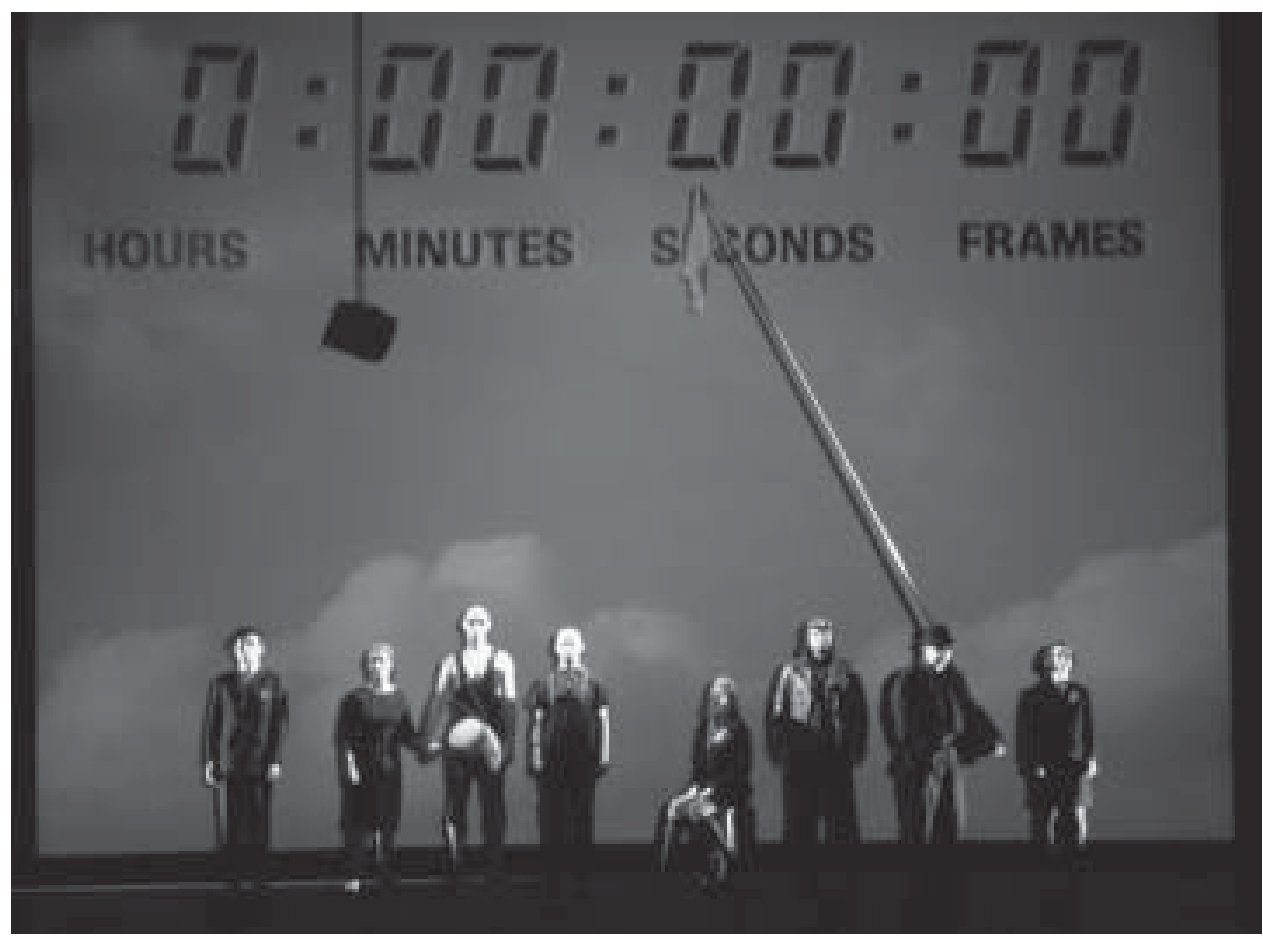

Figure 4. 0:00:00, The fall of the Wall. Jo Fabian's Pax Germania. Photo: Andreas Stirl. 
afterward, the smoking woman moves to the front of the stage and starts to reveal parts of her body in a striptease-like display (see Fig. 5). The man, whose comforting slaps turned into abuse in the first part of the choreography, endeavors unsuccessfully to convince her to quit her prostitution and to return to the line. The woman's refusal later turns into overly dramatic regret that shakes her body violently, a movement that seems reminiscent of the coughing from the piece's earlier part. Finally, she falls down to the ground, shaken by her crying. The short man, who was slapped, is the next to break out of the line. He even sends his former accuser back into the line, when hethe tall man with the drum on his waist-attempts to move forward. Because of the different context of the choreography and the gun now in his hand, the short man's nerdy attire's reference changes to a neo-fascist uniform. He repeatedly puts the tall man in line, as the tall man enthusiastically attempts to perform the rhythmic claps with the drumsticks above his head. Eventually, he makes the tall man collapse in the middle of the stage (see Fig. 6). Meanwhile the sound system persistently plays the line "the Wall fell" from a song, until the meaning of these words turns into background noise, thus losing any connection to a historical event.

The audience now seems to watch with more satisfaction. The viewers are entertained by the semblance of actions on stage. However, they soon realize that the movements' style is similar to the one performed before the clock turned zero. The action on stage seems to change because the dancers finally leave the line at the back of the stage and move into the up to now unexplored stage space in front of them. But still, the dancers perform and repeat abstractions of daily gestures. Fabian's choreography actively transforms the connotation of these movements in different contexts. As soon as this context changes, the meaning changes with it. A familiar movement can become strange and new just by performing it at another location, in this case away from the line of dancers at the back of the stage. The staging forces the audience

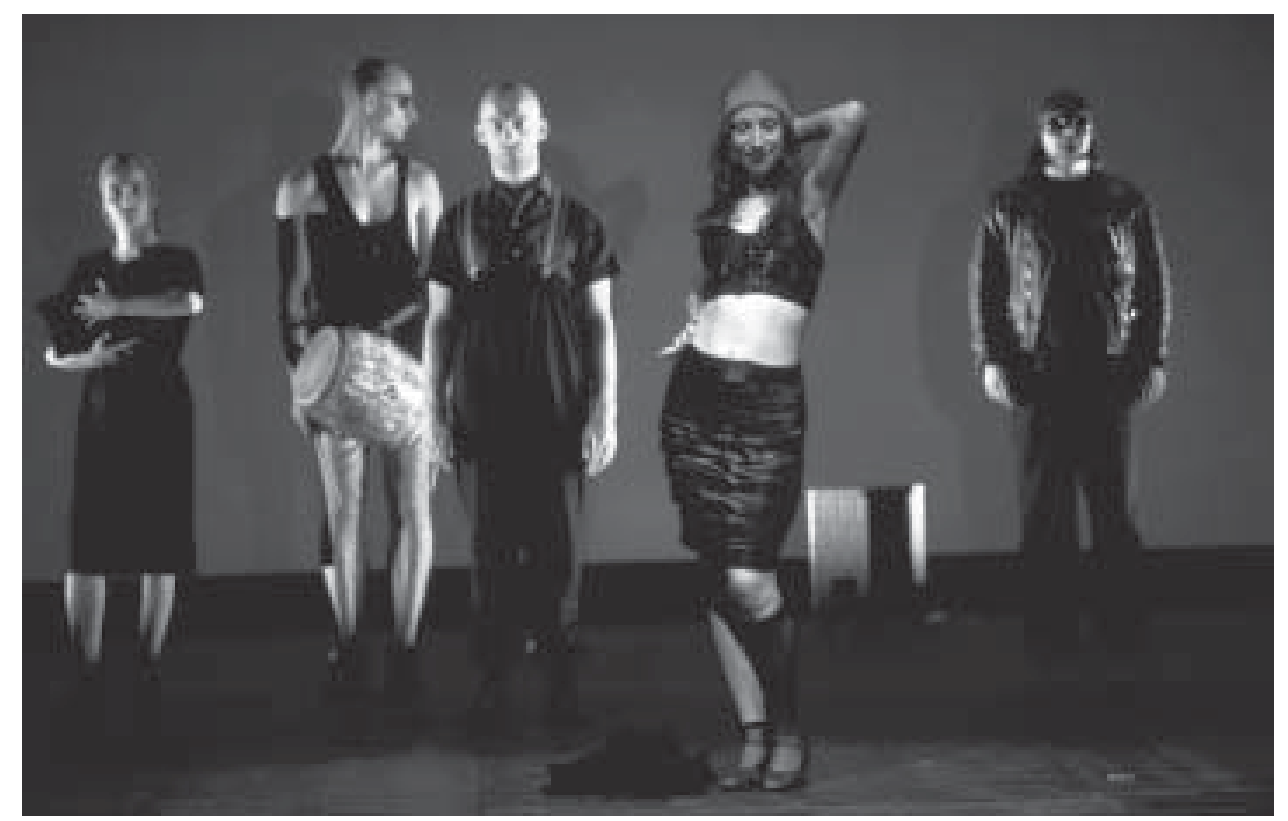

Figure 5. Breaking away from repetition after the fall of the Wall. Jo Fabian's Pax Germania. Photo: Andreas Stirl. 


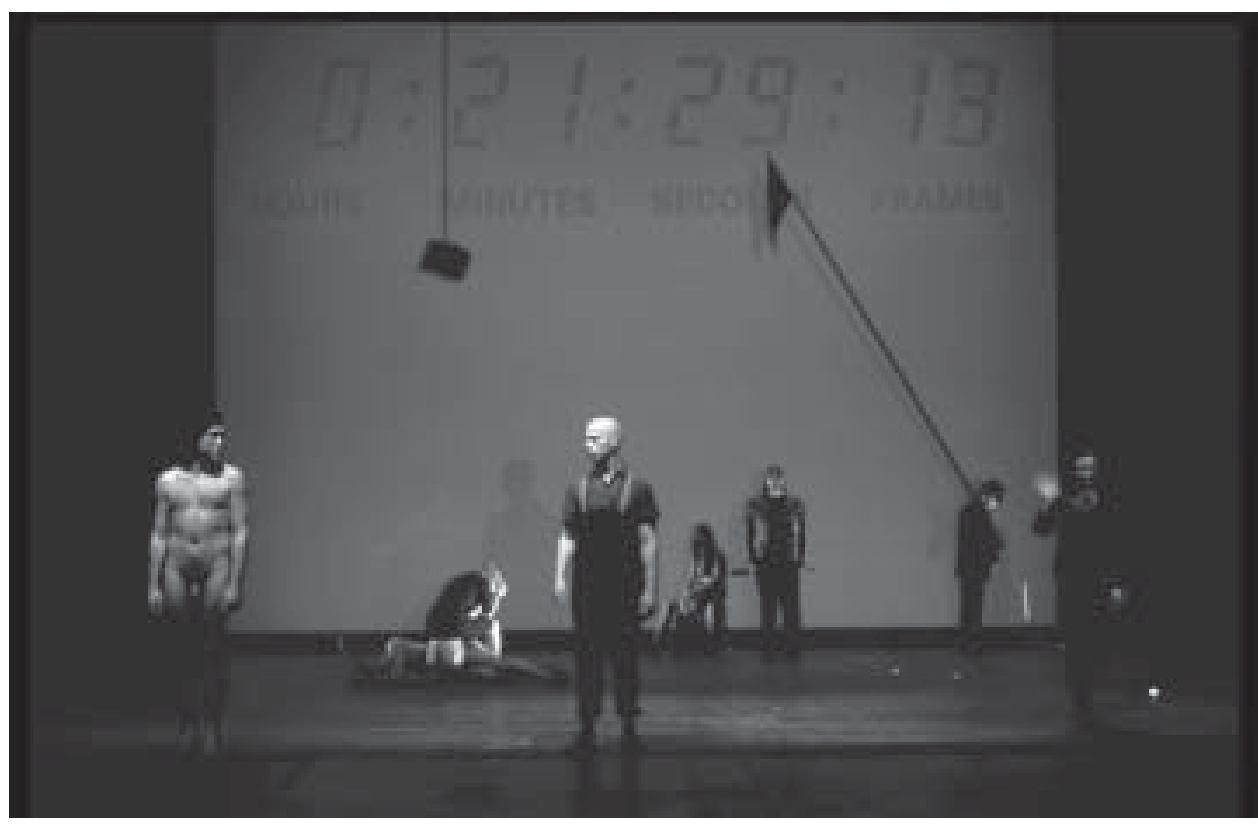

Figure 6. Near the end of Jo Fabian's Pax Germania. Photo: Andreas Stirl.

to participate in this modification of meanings, and in the process of doing so they may realize their position to the events on stage and to the actual historical situation in Germany. At the end of the performance, the following statement flashes at the audience: "We thank the originators of our history, without whom this evening wouldn't have been necessary." Audience members leave torn between amusement and anger, embarrassment and confusion.

In Pax Germania, Fabian combines a collective reminiscence of East German history with more current experiences in the unified Germany. He abstracts stereotypes from both time periods into a series of movements and postures by taking them out of their everyday context. The dancers repeat these movements or stand in their established postures. The audience members are pushed past boredom; unable to watch the monotony any longer, they start to act out their anger. Then, Fabian modifies the movement, spacing, and the pace of the choreography, only to fall back into another display of a corresponding sameness. As a result, he forces the audience members to observe the displayed movement and their own reaction to it more closely. Fabian employs dance theatre as a site for analysis of societal conditioning by manifesting the body's agency in history. Most importantly, he illustrates the significance of the dancing body as a site of resistance by comparing it to the moving body in pedestrian practices. Fabian's seemingly abstract choreography focuses on bodily movements in society and their relation to the dancing body on stage. The audience's resulting awareness of this causal correlation demonstrates corporeal reaction to social, political, and national interests. It also displays the ability of bodies and their movements to produce antonymous structures.

Similar to Fabian's staging in Pax Germania, Sasha Waltz appropriates pedestrian movement to illuminate social structures in her piece Allee der Kosmonauten. Waltz derives her choreography from a concrete social environment. While Fabian depicts 
social immobility through minimized and repetitious movement, Waltz questions family dynamics through a paroxysmal choreography of daily gestures and interaction with household items. Waltz does not clarify to whom or what the bodies surrender their authority and agency. Consequently, social power and agency turn into free-floating concepts that are only temporarily connected to the body in Waltz's work and are not grounded in historical experience and structures. Bodies in Waltz's choreography might react to their surroundings, but they never consciously refuse to participate nor do they create their own social situation.

Fabian, by contrast, choreographs a history lesson that mobilizes the audience. Moving bodies originated the German reunification, which in turn caused very concrete bodily movement in both Germanies. All this movement serves as a model for the abstraction staged by Fabian. His choreographed performance generates a bodily reaction from the audience. This corporeal process mirrors the creation of history by moving bodies and the influence of that history on bodies. Fabian does not provide any historical facts or individual stories. He turns general movements into a choreography that vividly embodies East German history before, during, and after the reunification. Fabian reveals that bodies are staged in history, and that they respond to the manipulation. But he also shows the bodies' capability to create their own history through movement. The final statement in the piece, "We thank the originators of our history, without whom this evening wouldn't have been necessary," confirms the cultural construction of history. By choreographing the individual's refusal and neglect to take agency in a historic situation, Fabian vividly points to the body's ability to claim this agency.

As in Fabian's choreography, East German citizens questioned the socialist state's naturalized claim on collective agency. Eventually, an assemblage of citizens' interdependent intentional acts of resistance lead to the overthrow of the East German government and the subsequent fall of the Berlin Wall. The walk across the bridge that connected East and West Berlin serves as a valuable example for the conscious application of choreographic tactics to an everyday situation. Theatrical recreations and embodied reflections on such movements are part of "a struggle for control over the way that memory will function." ${ }^{37}$ Yet, those who choreograph can materialize a major part of their decision-making processes by being aware of the inherent power of their position inside social systems as well as the agency in their movement choices. In turn, this awareness of memory, choreography, and potentiality can illuminate the role of embodiment in the creation of prospective societal structures.

\footnotetext{
${ }^{37}$ John Rouse, "Heiner Müller and the Politics of Memory," Theatre Journal 45 (1993): 65. Rouse's article contributes to Theatre Journal's special issue on German theatre of the fall of the Wall ten years ago. The contributing articles display an astonishing variety of views on the development in German theatre and approaches to historicizing of the social changes in Germany. Yet, ten years after the publication of this special issue, one can't help but read a shared nostalgia and uncertainty in several of the articles, due to the ongoing dramatic transformations in East German social and cultural landscape at that time that seem to erase East German culture. Meanwhile, this East German culture is mostly memory and relegated to anecdotal material. See several publications that structure East German history as anecdotal memory. Jana Hensel, Zonenkinder (Reinbeck bei Hamburg: Rowohlt Verlag GmbH, 2002), Katrin Aehnlich, Wenn ich groß bin, flieg ich zu den Sternen (Lemfoerde: Gustav Kiepenheuer Verlag, 1998), Alexander Osang, Die Nachrichten (Frankfurt am Main: Fischer Verlag, 2000), or Alexander Osang, 89: Helden-Geschichten (Berlin: Ch. Links Verlag: 2002). Yet it is still interesting to study this erasure and appropriation process not only to understand the different function that such memories now have in Germany but also to better understand transformations during such processes as the ongoing merger in the European Union or further globalization.
} 